\title{
Cutaneous Manifestations of Diabetes Mellitus
}

\author{
Study from Farwaniya Hospital, Kuwait
}

\author{
Nawaf Al-Mutairi Amr Zaki Ashok Kumar Sharma Mazen Al-Sheltawi
}

Department of Dermatology, Farwaniya Hospital, Kuwait

\section{Key Words}

Diabetes mellitus · Cutaneous manifestations

\begin{abstract}
Objective: To study the prevalence of cutaneous disorders in patients with diabetes mellitus. Subjects and Methods: All diabetic patients attending the Department of Dermatology, Al-Farwaniya Hospital, Kuwait, and diabetic in-patients with skin disorders were examined over a period of 18 months from March 2004 to August 2005. A total of 106 diabetic patients displaying 1 or more dermatological manifestations were identified and thoroughly examined for any skin disorder. The diabetic profile of the patients was obtained from medical records. Results: Of the 106 patients, 69 had only 1 cutaneous manifestation, 27 had 2, 6 had 3 and 4 had 4. Infections (68.0\%) were the major cutaneous manifestations with fungal infection occurring in 41 patients followed by bacteria in 27. The second most common presenting symptom was pruritus. Hypertension (74\%) was the most common systemic complication, and most of the diabetic patients who developed cutaneous manifestations were in the 40- to 60-year age group. Conclusions: The data show that infections were the most common cutaneous manifestation and hypertension the most common systemic complication.

Copyright $\odot 2006$ S. Karger AG, Basel
\end{abstract}

\section{Introduction}

Diabetes mellitus (DM) is the most common endocrine disorder [1]. The cutaneous manifestations of DM are well known and considered as common, as observed in $30-71 \%$ of diabetic patients $[1,2]$. The exact pathogenesis of most of these dermatoses is unknown. It is reasonable to assume that vessel and connective tissue alterations as well as the impairment of the immune system and other associated metabolic changes caused by diabetes play an important role. DM is common in Kuwait; about $15 \%$ of the adult Kuwaiti population has type $2 \mathrm{di}$ abetes [3] and the prevalence of type 1 diabetes is 269.9 per 100,000 Kuwaiti children [4]. Although diabetes is common in Kuwait, systematic surveys of the cutaneous manifestations in diabetic patients are lacking. Therefore the aim of our study was to evaluate the frequency of skin manifestations in these patients with diabetes.

\section{Subjects and Methods}

The study was conducted in the Department of Dermatology, Al-Farwaniya Hospital, Kuwait. The protocol for this study was approved by the hospital's Ethics Committee. All diabetic patients attending the Dermatology Out-Patient Clinic and diabetic inpatients with skin problems were examined over a period of 18 months from March 2004 to August 2005. A diagnosis of diabetes was made using uniform criteria: symptoms of diabetes plus random blood glucose concentration $\geq 11.1 \mathrm{mmol} / \mathrm{l}(200 \mathrm{mg} / \mathrm{dl})$ or fasting plasma glucose $\geq 7.0 \mathrm{mmol} / \mathrm{l}(126 \mathrm{mg} / \mathrm{dl})$ or 2 -hour plasma

\begin{tabular}{ll}
\hline KARGER & (c) 2006 S. Karger AG, Basel \\
Fax +41 61 306 $12341-7571 / 06 / 0156-0427 \$ 23.50 / 0$ \\
$\begin{array}{l}\text { E-Mail karger@karger.ch } \\
\text { www.karger.com }\end{array}$ & $\begin{array}{l}\text { Accessible online at: } \\
\text { www.karger.com } / \mathrm{mpp}\end{array}$
\end{tabular}

Dr. Nawaf Al-Mutairi PO Box 280 Farwaniya (Kuwait) Tel. +965937 0203, Fax +9654808167 E-Mail nalmut@usa.net 
Table 1. General profile of 106 diabetic patients

\begin{tabular}{lc}
\hline Parameter & Observations \\
\hline $\begin{array}{l}\text { Sex distribution } \\
\text { Male:female }\end{array}$ & $68: 38$ \\
Total & 106 \\
\hline Age distribution of patients & \\
$>0-20$ years & $5(4.7 \%)$ \\
$>20-40$ years & $33(31.1 \%)$ \\
$>40-60$ years & $45(42.5 \%)$ \\
$>60-80$ years & $23(21.7 \%)$ \\
Total & 106 \\
\hline
\end{tabular}

Type of diabetes

Type 1

Type 2

Total 106

\section{Duration of diabetes}

$<5$ years 22

$>5-10$ years 25

$>10$ years $\quad 59$

Total 106

glucose $\geq 11.1 \mathrm{mmol} / 1$ (200 $\mathrm{mg} / \mathrm{dl})$ during an oral glucose tolerance test. In the absence of unequivocal hyperglycaemia and acute metabolic decompensation, these criteria were confirmed by repeat testing on a different day. Informed consent was obtained from the patients. The patients who were diagnosed as having DM following investigation of dermatological manifestations were also included in the study. Each subject underwent a thorough dermatological examination.

A working classification of cutaneous manifestations of DM into four groups was adopted [1], and an attempt was made to place the observed skin lesions into one of these four categories: (a) cutaneous conditions with strong associations with DM; (b) skin manifestations related to infectious origins; (c) skin manifestations related to complications of DM, and (d) skin lesions related to treatment of DM. Medical records of these patients were reviewed for information regarding duration of diabetes, daily medications, complications of diabetes such as retinopathy and neuropathy, fasting triglycerides, cholesterol levels and renal function. Relevant microbiological and histopathological investigations were carried out to confirm the clinical diagnosis on all the patients with cutaneous manifestations.

\section{Results}

The general profile of the patients is given in table 1 . Of the 106 patients, the majority (42.5\%) were between 40 and 60 years of age. Among patients presenting with skin complaints, there were more type 2 diabetics (93 pa-
Table 2. Cutaneous manifestations of DM in the patients

\begin{tabular}{|c|c|c|}
\hline Cutaneous manifestations & Cases & Percentage \\
\hline \multicolumn{3}{|c|}{ Cutaneous conditions with strong associations with DM } \\
\hline Diabetic dermopathy & 6 & 5.7 \\
\hline Diabetic thick skin & 1 & 1 \\
\hline Necrobiosis lipoidica & 1 & 1 \\
\hline Rubeosis faciei & 11 & 10.4 \\
\hline Acanthosis nigricans & 5 & 4.7 \\
\hline Diabetic bullae & 2 & 1.9 \\
\hline Xanthomas & 7 & 6.6 \\
\hline Scleredema adultorum & 1 & 1 \\
\hline Pruritus & 52 & 49 \\
\hline Acrochordons & 11 & 10.4 \\
\hline Vitiligo & 3 & 2.8 \\
\hline Granuloma annulare & 2 & 2 \\
\hline Lichen planus & 5 & 4.7 \\
\hline Acquired perforating dermatoses & 2 & 2 \\
\hline Total & 109 & \\
\hline \multicolumn{3}{|c|}{ Cutaneous conditions related to infectious origins } \\
\hline Fungal & 41 & 38.7 \\
\hline Bacterial & 27 & 25.5 \\
\hline Viral & 3 & 3 \\
\hline Total & 71 & \\
\hline \multicolumn{3}{|c|}{ Cutaneous conditions related to complications of DM } \\
\hline Diabetic neuropathy & 10 & 9.4 \\
\hline Diabetic ulcer & 2 & 2 \\
\hline Total & 12 & \\
\hline \multicolumn{3}{|c|}{ Cutaneous conditions related to treatment of DM } \\
\hline Sulphonylurea-related skin lesions & 3 & 3 \\
\hline Insulin lipo-atrophy & 3 & 3 \\
\hline Insulin-allergic reactions & 1 & 1 \\
\hline Total & 7 & \\
\hline
\end{tabular}

tients) than type 1 (13). Of the 106 patients, 88 (83\%) were known diabetics and 18 (17\%) were diagnosed as diabetics in the skin Out-Patient Department after investigation. Fifty-nine of the 88 patients have diabetes of over a 10 -year duration.

Cutaneous manifestations according to the four groups are given in table 2 . Pruritus was the most common in 52 patients, followed by fungal (41) and bacterial (27) infections. Sixty-nine patients $(65 \%)$ had only 1 manifestation, 27 (25.5\%) had 2, $6(5.7 \%)$ had 3 and 4 (3.8\%) had 4. Types of fungal, bacterial and viral infections are given in table 3. Tinea pedis was the most common fungal infection while folliculitis was the most common bacterial infection. Three patients had recurrent herpes simplex. Cutaneous infections were found to be more common during the first 5 years of diabetes ( 46 
Table 3. Type of infection seen among diabetic patients

\begin{tabular}{lcc}
\hline Type of infection & Cases & Percentage \\
\hline Fungal infections & 5 & 7 \\
Tinea corporis & 4 & 5.6 \\
Tinea cruris & 15 & 21 \\
Tinea pedis & 2 & 2.8 \\
Tinea unguium & 3 & 4.2 \\
Paronychia & 7 & 9.9 \\
Candidal vulvovaginitis & 1 & 1.4 \\
Candidal balanoposthitis & 4 & 5.6 \\
Candidal intertrigo & 41 & 57.7 \\
Subtotal & & \\
\hline Bacterial infections & 14 & 19.7 \\
Folliculitis & 2 & 2.8 \\
Impetigo (bullous) & 1 & 1.4 \\
Furunculosis & 2 & 2.8 \\
Carbuncle & 4 & 5.6 \\
Cellulitis & 1 & 1.4 \\
Infectious eczematoid dermatitis & 3 & 4.2 \\
Erythrasma & 27 & 38 \\
Subtotal & & \\
\hline Viral infections & 3 & 4.2 \\
Herpes simplex & 3 & 4.2 \\
Subtotal & & \\
\hline
\end{tabular}

Table 4. Diabetic complications/associations in 61 patients

\begin{tabular}{lc}
\hline Complications & Cases \\
\hline Retinopathy & 7 \\
Nephropathy & 2 \\
Neuropathy & 18 \\
Hyperlipidemias & 10 \\
Hypertension & 44 \\
Coronary artery disease & 4 \\
Peripheral vascular disease & 3 \\
Total & 88 \\
\hline
\end{tabular}

The total number exceeds the number of patients (61) because many showed more than 1 complication/association.

patients). Of the 7 patients with xanthomas, 3 had an eruptive variant and in addition had hypertriglyceridaemia.

The systemic complications and associations of DM with cutaneous manifestations are shown in table 4 .
Many of the patients had more than 1 underlying systemic complication. Hypertension was observed in 44 patients.

\section{Discussion}

Similar to a previous study [5], male patients outnumbered female patients (table 1) in our study, but not in another study [6] in which there were more female patients.

The majority of our patients were in the 40 - to 60 -year age group, an observation also noted by other researchers $[5,6]$. The relative increase in the incidence of cutaneous involvement with age in diabetic patients may be attributed merely to the long duration of diabetes in these patients.

The majority of patients in this study had type $2 \mathrm{DM}$, as has been noted in other studies $[5,6]$, apparently reflecting the general distribution pattern of type 1 and type $2 \mathrm{DM}$ cases in world populations $[1,5]$. No difference in the prevalence of cutaneous disorders between type 1 and type $2 \mathrm{DM}$ patients has been noted $[1,5]$.

Among the cutaneous disorders observed in our DM patients, infections comprised the largest group affecting $67 \%$ of the cases, similar to previous reports $[5,6]$. It is well known that diabetic patients are susceptible to infections probably due to hyperglycaemia and defects in polymorphonuclear leucocyte function [7]. Surprisingly, viral infections in diabetic patients have not been reported in previous studies as observed in our study where 3 diabetic patients showed recurrent herpes simplex. It is difficult to say whether it is an incidental observation or whether compromised resistance of the diabetic state is somehow responsible for precipitating the recurrences.

Pruritus was the second most common manifestation among our diabetic patients and was seen in $49 \%$ of patients in the present study. Similar observations have been reported [6], including a review that questions the relationship between generalized itching and DM [8]. However, we believe that generalized itching, at least in some DM cases, cannot be readily explained by any other cause except by the underlying DM.

The $5.7 \%$ of patients with diabetic dermopathy observed in this study falls within the range of previous reports of 3.5-9.37\% [5, 6]. While a comprehensive review on the subject considers diabetic dermopathy to be the most common manifestation in DM [1], we did not observe it to be so common. 
The $1 \%$ of patients with necrobiosis lipoidica observed in this study is similar to that reported by Nigam and Pande [5] although Mahajan et al. [6] did not make a similar observation. It is generally well known that necrobiosis lipoidica is not common in diabetic patients with a reported incidence of $0.3-1.6 \%$ [1]. Dermatoses associated with an increased incidence of DM, like vitiligo, lichen planus and acquired perforating dermatoses detected in the present study, have been reported previously [1].

An attempt was made to note the underlying systemic complications attributed to DM in our patients. Hypertension (44 patients) was identified as the one systemic feature most common in our diabetic patients showing cutaneous involvement consistent with the previous report of Mahajan et al. [6] which also included retinopathy among others. Hypertension has been hypothesized to accelerate the process of micro-angiopathy in diabetics [6].

\section{Conclusion}

Most of the diabetic patients who developed cutaneous manifestations were in the 40 - to 60 -year age group, and infections were the single largest type of involvement while the most common systemic complication of diabetes was hypertension.

\section{References}

$>1$ Paron NG, Lambert PW: Cutaneous manifestations of diabetes mellitus. Prim Care 2000;27:371-383.

-2 Yosipovitch G, Hodak E, Vardi P, Shraga I, Karp M, Sprecher E, David M: The prevalence of cutaneous manifestations in IDDM patients and their association with diabetes risk factors and microvascular complications. Diabetes Care 1998;21:506-509.
13 Akanji AO: Diabetic dyslipidaemia in $\mathrm{Ku}$ wait. Med Princ Pract 2002;11:47-55.

4 Moussa MA, Alsaeid M, Abdella N, Refai TM, Al-Sheikh N, Gomez GE: Prevalence of type I diabetes among 6- to 18-year-old Kuwaiti children. Med Princ Pract 2005;14:8791.

5 Nigam PK, Pande S: Pattern of dermatoses in diabetics. Indian J Dermatol Venereol Leprol 2003;69:83-85.
6 Mahajan S, Koranne RV, Sharma SK: Cutaneous manifestation of diabetes mellitus. Indian J Dermatol Venereol Leprol 2003;69: 105-108.

7 Kemmerly SA: Dermatologic manifestations of infections in diabetics. Infect Dis Clin North Am 1994;8:523-532.

8 Jelinek JE: Cutaneous manifestations of diabetes mellitus. Int J Dermatol 1994;33:605617. 